\title{
Seventeenth Conference of Arab Red Crescent and Red Cross Societies
}

Following an invitation from the General Secretariat of Arab Red Crescent and Red Cross Societies, the ICRC President, accompanied by the delegate-general for the Middle East and North Africa, took part in the Seventeenth Conference of Arab Red Crescent and Red Cross Societies, which was held at Nouakchott from 15 to 17 March.

The ICRC representatives gave a report on the activities of the Committee in the Middle East and more particularly in the People's Democratic Republic of Yemen. The report aroused keen interest among the participants.

At the end of its session the Conference adopted a series of resolutions, one of which concerns the ICRC directly. In substance, the resolution calls on the ICRC to pursue its assistance activities on behalf of the victims of current conflicts in the Middle East and, on the other hand, urges National Societies in Arab countries to encourage their governments to accede to the Protocols additional to the Geneva Conventions.

\section{Second Asia and Pacific workshop on the dissemination of international humanitarian law}

The Second Asia and Pacific workshop on the dissemination of international humanitarian law was held at Kuala Lumpur from 5 to 11 May. It was organized jointly by the Malaysian Red Crescent Society and the ICRC, and brought together about fifty participants from 23 National Red Cross and Red Crescent Socie- 
ties. The opening ceremony was held in the presence of Mr. Alexandre Hay, President of the ICRC, and Y.B. Dato Abu Hassan bin Haji Omar, Minister of Welfare Services of Malaysia.

The ICRC was also represented by Mr. Alain Modoux, Head of the Information Department, and five other staff members, including three dissemination delegates based in different countries of the region. The League had delegated Dr. Kingsley Seeveratnam, Head of the Asia and Pacific Department.

This workshop dealt with the means and methods of dissemination (the first one, which was held in the same city in November 1978, had dealt with the substance of international humanitarian law) and was marked by the high quality and the pragmatic nature of the papers presented. Moreover, the work in groups was very conducive to fruitful exchanges of views and experiences. The participation of communication experts from outside the Red Cross Movement proved to be extremely positive and stimulating. Each day's discussions were devoted to a specific target group (Red Cross and Red Crescent volunteers, young people, academic circles, the mass media) and the introductory paper was presented each time by an outside specialist fully acquainted with the concerns of the target group in question. 